\title{
ASTHMA
}

\section{Smoking and the incidence of asthma during adolescence: results of a large cohort study in Germany}

\author{
J Genuneit, G Weinmayr, K Radon, H Dressel, D Windstetter, P Rzehak, C Vogelberg, \\ W Leupold, D Nowak, E von Mutius, S K Weiland
}

See end of article for authors' affiliations

.....................

Correspondence to: Prof Dr med S K Weiland, Department of Epidemiology, University of Ulm, Helmholtzstr 22, D-89081 Ulm, Germany; stephan.weiland@uni-ulm.

Received 8 August 2005 Accepted

26 February 2006

Published Online First

14 March 2006
Background: The association between smoking and asthma or wheeze has been extensively studied in cross sectional studies, but evidence from large prospective cohort studies on the incidence of asthma during adolescence is scarce.

Methods: We report data from a cohort study in two German cities, Dresden and Munich. The study population $(n=2936$ ) was first studied in 1995 /6 at age 9-11 years as part of phase Il of the International Study of Asthma and Allergies in Childhood (ISAAC II) and followed up in 2002/3. At baseline the parents completed a questionnaire and children underwent clinical examination and blood sampling. At follow up the young adults completed questionnaires on respiratory health, living, and exposure conditions. Incidence risk ratios (IRR) were calculated and adjusted for potential confounders using a modified Poisson regression approach.

Results: The adjusted IRR for incident wheeze for active smokers compared with non-smokers was 2.30 195\% confidence interval (CI) 1.88 to 2.82 ). The adjusted IRR was slightly higher for incident wheeze without a cold $(2.76,95 \% \mathrm{Cl} 1.99$ to 3.84$)$ and the incidence of diagnosed asthma $(2.56,95 \% \mathrm{Cl} 1.55$ to 4.21). Analysis of duration and intensity of active smoking indicated dose dependent associations. Stratified analyses showed that the risk of incident wheeze without a cold in atopic smokers increased with decreasing plasma $\alpha_{1}$-antitrypsin levels at baseline (1.64, 95\% Cl 1.22 to 2.20 per interquartile range). Conclusions: Active smoking is an important risk factor for the incidence of asthma during adolescence. Relatively lower plasma levels of $\alpha_{1}$-antitrypsin, although well above currently accepted thresholds, may increase susceptibility to respiratory disease among atopic smokers.
$\mathrm{D}$ eterminants of asthma and wheeze have been extensively studied in cross sectional studies. However, this study design has a major limitation in its inability to establish a temporal sequence between exposure and disease. Evidence from birth cohort studies on risk factors for the incidence of asthma is currently emerging from several countries, but most cohorts are still relatively young. Evidence from cohort studies on risk factors for asthma incidence during adolescence is scarce.

The results from available cohort studies on the role of active smoking are conflicting. While some studies observed an increased incidence of asthma among smokers, ${ }^{1-6}$ some found no effect or weak associations, ${ }^{78}$ and one group reported an inverse relation. ${ }^{9}$ Only two of these studies provide data on adolescents. ${ }^{16}$ Exposure to environmental tobacco smoke (ETS) is also thought to be a risk for the incidence of respiratory disease. ETS exposure seems to cause an increase in non-atopic wheezy bronchitis in children whereas, in children with established asthma, parental smoking is associated with more severe disease. ${ }^{10}{ }^{11}$ In addition, ETS exposure seems to be a risk factor for chronic bronchitis and asthma in adults. ${ }^{12}$ However, longitudinal data on adolescents are again limited and only one study showed a significant association between maternal smoking and the incidence of asthma in their children. ${ }^{11}$

Apart from the lack of longitudinal data concerning risk factors for asthma, there is also increasing interest in interactions of environmental exposures with genetic predisposition and in markers for susceptibility. Attention has recently been drawn to the harmful effect of glutathione-S-transferase deficiency and of low plasma $\alpha_{1}$-antitrypsin levels in combination with exposure to ETS. ${ }^{13}{ }^{14} \alpha_{1}$-Antitrypsin is a serine protease inhibitor which primarily binds elastase produced by neutrophils during inflammation, preventing elastic tissue like the lung from degeneration. ${ }^{15}$

In this paper we present data from a large population based cohort study in Germany. The study population comprised 2936 children aged 9-11 years at baseline and followed for about 7 years through adolescence. The objective was to investigate the role of active and passive smoking on the incidence of asthma. In addition, we examined differences in susceptibility to respiratory disease associated with atopy, smoking, and $\alpha_{1}$-antitrypsin blood plasma levels.

\section{METHODS}

Study population and study design

The baseline population consisted of 9-11 year old participants in phase II of the International Study of Asthma and Allergies in Childhood (ISAAC II) in Munich and Dresden in 1995/6. ${ }^{16}$ Details of the surveys have been described elsewhere. ${ }^{17}$ Briefly, parents of random samples of fourth grade pupils in Munich $(\mathrm{n}=3354$, response rate $87.5 \%)$ and in Dresden $(n=3045$, response rate $83.0 \%)$ responded to a written questionnaire. Detailed information on respiratory health, living, and exposure conditions was collected.

Abbreviations: BMI, body mass index; CRP, C-reactive protein; ETS, environmental tobacco smoke; IRR, incidence risk ratio; SES, socioeconomic status 


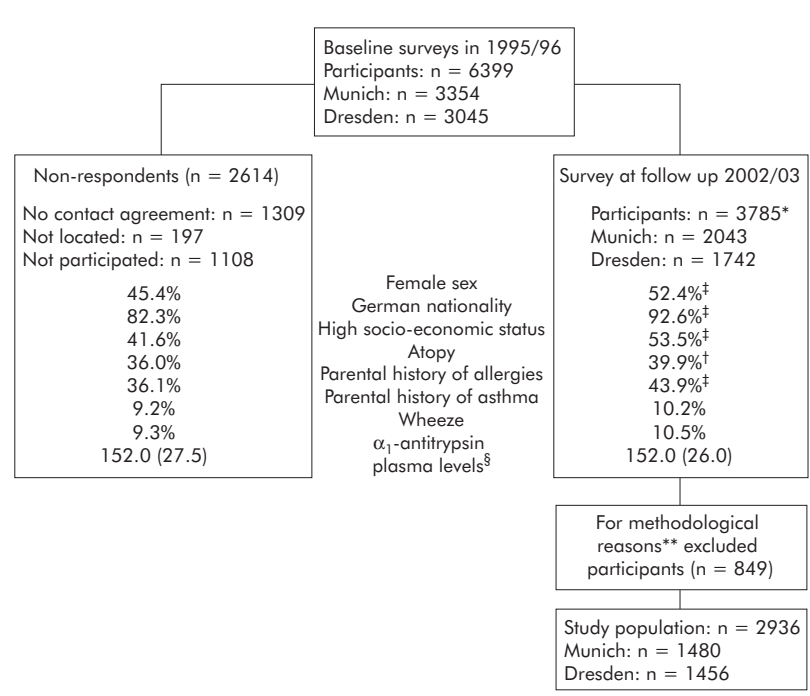

Figure 1 Characteristics of non-respondents $(n=2614)$ and follow up participants $(n=3785)$. \% = prevalence. *Participation rate: $77.4 \%$ of those located; $\mathrm{tp}<0.05 ; \mathrm{t}<0.001 ;$ Smedian (interquartile range) $\mathrm{mg} / \mathrm{dll}$; ${ }^{*}$ details given in the Methods section.

The characteristics of the participants in the follow up survey $(n=3785)$ and of the study population included in the analyses $(n=2936)$ are shown in fig 1 and table 1 . We excluded 849 participants from the analyses for the following reasons: (1) Non-German nationality $(n=293)$. In Germany, nationality reflects ethnicity rather than place of birth. It is known that in Germany the prevalence of asthma and allergies is much higher among children with German nationality than in those without. $^{18}$ The proportion of participants without German nationality differed substantially between the two study centres (Dresden $0.2 \%$, Munich $13.5 \%$ ). (2) Reported wheeze or asthma during the baseline survey $(\mathrm{n}=494)$ since this study was on the incidence of wheeze and asthma. (3) Missing values for wheeze or asthma at baseline or wheeze at follow up $(n=62)$.

The studies at baseline were approved by the ethics committee of the University of Münster, Germany and the follow up study was approved by the ethical committees of the Bavarian Chamber of Physicians and of the Department of Medicine, Technical University of Dresden.

\section{Questionnaires and clinical examination, blood sampling and laboratory analysis}

The baseline questionnaire consisted of the questionnaire from the German ISAAC phase II study described in detail elsewhere. ${ }^{17}$ The follow up questionnaire consisted mainly of items from the European Community Respiratory Health Survey (ECRHS) and ISAAC. ${ }^{16}{ }^{19}$ The items in question were respiratory symptoms and disease as well as allergies among participants and their families, sociodemographic characteristics, active and passive smoking, present and previous living conditions, and several occupational aspects.

At baseline, measurements $(\mathrm{n}=2088,71.1 \%)$ of specific serum IgE antibodies directed against a panel of common aeroallergens (mixed grass pollen, birch pollen, mugwort pollen, Dermatophogoides pteronyssinus, cat dander, dog dander, Cladosporium herbarum) were conducted by fluorescence enzyme immunoassay (SXl CAP; Pharmacia, Lund, Sweden). Skin prick tests $(\mathrm{n}=2500,85.1 \%)$ were performed using extracts of six common aeroallergens ( $D$ pteronyssinus, $D$ farinae, Alternaria tenius, cat hair, mixed tree and mixed grass pollen). A random subsample underwent spirometric testing and bronchial challenge using hypertonic saline $(\mathrm{n}=1227$, $41.8 \%) .{ }^{14}$ Plasma levels of $\alpha_{1}$-antitrypsin were measured in
Table 1 Characteristics of the study population $(n=2936)$

\begin{tabular}{|c|c|c|}
\hline & $\begin{array}{l}\text { Baseline } \\
\text { n }(\%)^{*}\end{array}$ & $\begin{array}{l}\text { Follow up } \\
\text { n }(\%)^{*}\end{array}$ \\
\hline Mean (SD) age (years) & $9.6(0.56)$ & $17.1(0.62)$ \\
\hline \multicolumn{3}{|l|}{ Sex } \\
\hline Female & $1592(54.2)$ & $1592(54.2)$ \\
\hline Male & $1344(45.8)$ & $1344(45.8)$ \\
\hline \multicolumn{3}{|l|}{ Symptoms and diagnosis of respiratory disease } \\
\hline Incident wheeze (yes) & NA & $388(13.2)$ \\
\hline Incident wheeze without a cold (yes) & NA & $158(5.8)$ \\
\hline Incidence of diagnosed asthma (yes) & NA & $66(2.6)$ \\
\hline \multicolumn{3}{|l|}{ Parental history of } \\
\hline Allergic disease (yes) & $1258(43.2)$ & NA \\
\hline Asthma (yes) & $241(9.0)$ & NA \\
\hline \multicolumn{3}{|l|}{ Clinical examination } \\
\hline Bronchial hyperreactivity (yes) & $186(15.2)$ & NA \\
\hline Atopyt (yes) & $780(36.6)$ & NA \\
\hline Median (IQR) plasma $\alpha_{1}$-antitrypsin (mg/dl) & $152.0(25.0)$ & NA \\
\hline Active smoking during adolescence (yes) & NA & $993(34.1)$ \\
\hline Mean (SD) age at onset of smoking (years) & NA & $14.1(1.54)$ \\
\hline \multicolumn{3}{|l|}{ Duration of active smoking } \\
\hline Never & NA & $1922(66.4)$ \\
\hline$\leqslant 2$ years & NA & $395(13.6)$ \\
\hline $2-4$ years & NA & $422(14.6)$ \\
\hline$>4$ years & NA & $156(5.4)$ \\
\hline Mean (SD) duration of active smoking (years) & NA & $2.6(1.35)$ \\
\hline \multicolumn{3}{|l|}{ Intensity of active smoking } \\
\hline Never & NA & $1922(66.1)$ \\
\hline Occasionally & NA & $169(5.8)$ \\
\hline Daily $\leqslant 10$ cigarettes & NA & $440(15.1)$ \\
\hline Daily $>10$ cigarettes & NA & $378(13.0)$ \\
\hline Exposure to ETS (yes) & 1094 (38.9) & $1863(63.9)$ \\
\hline Exposure to ETS at home (yes) & $1094(38.9)$ & $920(40.2)$ \\
\hline \multicolumn{3}{|l|}{ Duration of ETS exposure } \\
\hline Never & NA & $997(34.4)$ \\
\hline$\leqslant 1 \mathrm{~h} /$ day & NA & $560(19.3)$ \\
\hline $1-5$ h/day & NA & $863(29.8)$ \\
\hline$>5 \mathrm{~h} /$ day & NA & $478(16.5)$ \\
\hline
\end{tabular}

$\%$, prevalence; SD, standard deviation; IQR, interquartile range; ETS, environmental tobacco smoke; NA, not applicable/assessed. *Unless otherwise specified.

†Atopy is defined as either at least one positive skin prick test (wheal size $\geqslant 3 \mathrm{~mm}$ after subtraction of negative control) or specific serum lgE levels $>0.7 \mathrm{kU} / \mathrm{l}$ (a panel of common aeroallergens tested for both).

samples from 2015 children $(68.6 \%)$ using the rate nephelometric Immuno-Chemistry System (ICS Aray; Beckman Instruments, Fullerton, CA, USA). ${ }^{16}$ C-reactive protein (CRP) levels were measured in plasma $(\mathrm{n}=2018,68.7 \%)$ by standard densiometry (Vitro 250; Johnson \& Johnson, Rochester, NY, USA).

\section{Definitions of variables}

Outcome variables

We defined wheeze as either presence of "wheezing or whistling in the chest" or asthma medication use in the past 12 months. Wheeze without a cold was an affirmative response to the question "Have you had this wheezing or whistling when you did not have a cold?". Subjects were defined as having diagnosed asthma if they had wheeze and reported that a doctor had either diagnosed "asthma" at least once or "spastic/asthmatic bronchitis" at least twice. Atopy was assessed only at baseline and defined as either at least one positive skin reaction (wheal size $\geqslant 3 \mathrm{~mm}$ after subtraction of negative control) to the six tested aeroallergens or specific serum IgE levels $>0.7 \mathrm{kU} / . .^{20}$

\section{Explanatory variables}

Active smoking was determined by responses to "Have you ever smoked for as long as a year? ("yes" means at least 20 packs of cigarettes in a lifetime, or at least one cigarette per day or one cigar a week for one year)" (yes/no). Age at the onset of active smoking and age at quitting were reported in 
years. Duration of active smoking was calculated as the difference of the age at onset of smoking and the age at follow up or, if applicable, the age at quitting. Intensity of active smoking was obtained by responses to "How often have you smoked cigarettes in the last month?" and combined into four categories for analyses (never, occasionally, daily $\leqslant 10$ cigarettes, daily $>10$ cigarettes) to conform to WHO guidelines and smoking definitions widely used in the medical literature.

Exposure to ETS was evaluated by the question: "Does anybody at present smoke inside your child's home?" (yes/no) at baseline and by the question: "Have you been regularly exposed to tobacco smoke in the last 12 months? "regularly" means on most days or nights)" (yes/no) at follow up. The duration of ETS exposure at follow up was determined as reported in hours/day at home, at the workplace, in bars, restaurants, movie theatres, or similar places, and at other places. For analyses the sum of all responded hours was categorised into never, $\leqslant 1 \mathrm{~h} /$ day, $1-5 \mathrm{~h} /$ day, and $>5 \mathrm{~h} /$ day.

\section{Putative confounding variables}

The following variables were assessed at baseline and tested as putative confounders in the models: atopy, bronchial hyperreactivity, sex, study centre, age (at follow up, continuously), parental history of allergies (at least one parent reporting a lifetime history of asthma, hayfever, or atopic dermatitis), parental history of asthma, socioeconomic status (SES), dampness or mould in the dwelling, exposure to heavy truck traffic, body mass index (BMI), and ETS exposure. BMI and ETS exposure at follow up were also tested as putative confounders. BMI was computed as weight $(\mathrm{kg})$ divided by the square of height $\left(\mathrm{m}^{2}\right)$. Cut points for underweight and overweight were the 10th and 90th percentiles, respectively, according to the distribution of BMI among the German population. ${ }^{21}$ SES was considered high if either parent had attended school for at least 12 years.

\section{Statistical methods}

Participants with missing values were excluded from analyses involving the respective variable. Three subjects reported extreme ages at onset of smoking ( 7 years and earlier) and were excluded from the analyses of onset and duration of active smoking. Subjects with plasma CRP levels higher than $1 \mathrm{mg} / \mathrm{dl}$ (sensitivity of laboratory analyses to detect CRP was $0.6 \mathrm{mg} / \mathrm{dl}$ ) were regarded to have acute inflammation and were excluded from the analyses of plasma $\alpha_{1}$-antitrypsin levels $(n=48)$.
Incidence risk ratios (IRR) were estimated using a modified Poisson regression approach. ${ }^{22}{ }^{23}$ The comparison was always made between incident cases and participants who never reported the respective outcome. $\mathrm{p}$ values from a $\chi^{2}$ test are denoted as $\mathrm{p}_{\chi_{2}}$. Confounding or interaction with the main exposure variable was tested for the confounding variables mentioned above. Confounding was defined by change of $\geqslant 15 \%$ in the estimated coefficient of the main exposure variable by one or joint confounders. Interaction was presumed if the interaction term was significant with a $\mathrm{p}<0.05$ and found consistently for the three outcomes. All multivariate models included sex, age, and study centre regardless of the confounding effect. Generally, adjustments did not alter the direction of the observed effect and only changed statistical significance of estimates in three models; we therefore do not report crude IRR in the interest of brevity. Information on the number of cases and non-cases, however, is given in the tables. All computations were performed using SAS Software Version 8.02 (SAS Institute Inc, Cary, NC, USA).

\section{RESULTS}

The study population consisted of almost equal numbers in Dresden and Munich with more females than males (table 1). At baseline the prevalence of atopy was $36.6 \%$ and the prevalence of bronchial hyperreactivity was $15.2 \%$. About one third of the subjects were classified as active smokers at follow up. At baseline, 38.9\% experienced exposure to ETS at home and $40.2 \%$ at follow up. Almost 30\% reported daily exposure to ETS of $1-5$ hours at follow up.

Table 2 shows the incidence of wheeze and asthma in relation to active smoking during adolescence. The adjusted IRR for active smokers compared with non-smokers for incident wheeze was 2.30 (95\% CI 1.88 to 2.82 ). The adjusted IRR was higher for more severe outcomes-for example, 2.76 (95\% CI 1.99 to 3.84) for incident wheeze without a cold and 2.56 (95\% CI 1.55 to 4.21 ) for the incidence of diagnosed asthma. The analyses of duration and intensity of active smoking showed dose dependent associations before and after adjustment for covariates.

There was a significant interaction between atopy and active smoking for incident wheeze $(\mathrm{p}=0.0016)$, but not for incident wheeze without a cold $(p=0.1556)$ or for incident asthma $(p=0.9696)$. Because of the observed interaction and the potential for a better understanding of the disease aetiology, we performed the analyses of smoking effects on wheeze and asthma stratified by atopy (table 3 ). The pattern of associations resembled those of the unstratified analysis

Table 2 Incidence (\%) of wheeze or asthma between ages 9 and 17 in relation to active smoking during adolescence

\begin{tabular}{|c|c|c|c|c|c|c|}
\hline & \multicolumn{2}{|l|}{ Incident wheeze } & \multicolumn{2}{|c|}{ Incident wheeze without a cold } & \multicolumn{2}{|c|}{ Incidence of diagnosed asthma } \\
\hline & $\%(n / N)^{*}$ & $\begin{array}{l}\text { Adjusted IRR } \\
(95 \% \mathrm{Cl}) \dagger\end{array}$ & $\%(n / N)^{*}$ & $\begin{array}{l}\text { Adjusted IRR } \\
(95 \% \mathrm{Cl}) \dagger\end{array}$ & $\%(n / N)^{*}$ & $\begin{array}{l}\text { Adjusted IRR } \\
(95 \% \mathrm{Cl}) \dagger\end{array}$ \\
\hline \multicolumn{7}{|c|}{ Active smoking during adolescence } \\
\hline No & $8.4(160 / 1907)$ & & $3.2(58 / 1805)$ & & $1.6(27 / 1739)$ & \\
\hline Yes & $22.6(222 / 983)$ & 2.30 (1.88 to 2.82 ) & $11.4(98 / 859)$ & 2.76 (1.99 to 3.84$)$ & $4.7(37 / 780)$ & $2.56(1.55$ to 4.21$)$ \\
\hline \multicolumn{7}{|c|}{ Duration of active smoking (years) } \\
\hline Never & $8.4(160 / 1907)$ & & $3.2(58 / 1805)$ & & $1.6(27 / 1739)$ & \\
\hline$\leqslant 2$ & $16.8(65 / 388)$ & $1.82(1.38$ to 2.40$)$ & $8.0(28 / 351)$ & 2.13 (1.37 to 3.33$)$ & $2.5(8 / 323)$ & $1.43(0.65$ to 3.17$)$ \\
\hline $2-4$ & $24.3(102 / 419)$ & $2.45(1.92$ to 3.11$)$ & $10.7(38 / 355)$ & 2.55 (1.69 to 3.85$)$ & $5.7(19 / 331)$ & $3.11(1.71$ to 5.65$)$ \\
\hline$>4$ & $31.6(49 / 155)$ & $3.10(2.32$ to 4.15$)$ & $22.1(30 / 136)$ & 4.95 (3.24 to 7.57 ) & $7.3(8 / 110)$ & 3.97 (1.84 to 8.57 ) \\
\hline \multicolumn{7}{|c|}{ Intensity of active smoking } \\
\hline Never & $8.4(160 / 1907)$ & & $3.2(58 / 1805)$ & & $1.6(27 / 1739)$ & \\
\hline Occasionally & $14.3(24 / 168)$ & 1.58 (1.06 to 2.36$)$ & $7.7(12 / 156)$ & 2.13 (1.17 to 3.87$)$ & $2.7(4 / 146)$ & $1.63(0.58$ to 4.58$)$ \\
\hline Daily $\leqslant 10$ cigs & $19.5(85 / 435)$ & $2.13(1.66$ to 2.74$)$ & $9.3(36 / 386)$ & 2.42 (1.61 to 3.64$)$ & $4.3(15 / 352)$ & 2.46 (1.31 to 4.63$)$ \\
\hline Daily >10 cigs & $29.7(111 / 374)$ & $2.95(2.31$ to 3.77$)$ & $16.0(50 / 313)$ & 3.66 (2.47 to 5.43$)$ & $6.5(18 / 278)$ & $3.34(1.80$ to 6.19$)$ \\
\hline
\end{tabular}

$\mathrm{n}$, cases; $\mathrm{N}$, total of exposed; IRR, incidence risk ratio; $\mathrm{Cl}$, confidence interval.

*Population comprises subjects without missing values for the outcome, exposure, and confounding variables.

†All models adjusted for sex, age, study centre, and duration of exposure to environmental tobacco smoke (ETS) at follow up (for further detail see Methods). 
Table 3 Incidence (\%) of wheeze or asthma between ages 9 and 17 in relation to active smoking during adolescence by atopy at baseline

\begin{tabular}{|c|c|c|c|c|c|c|}
\hline & \multicolumn{2}{|l|}{ Incident wheeze } & \multicolumn{2}{|c|}{ Incident wheeze without a cold } & \multicolumn{2}{|c|}{ Incidence of diagnosed asthma } \\
\hline & $\%(n / N)^{*}$ & $\begin{array}{l}\text { Adjusted IRR } \\
(95 \% \mathrm{Cl}) \dagger\end{array}$ & $\%(\mathrm{n} / \mathrm{N})^{*}$ & $\begin{array}{l}\text { Adjusted IRR } \\
(95 \% \mathrm{Cl}) \dagger\end{array}$ & $\%(\mathrm{n} / \mathrm{N})^{*}$ & $\begin{array}{l}\text { Adjusted IRR } \\
(95 \% \mathrm{Cl}) \dagger\end{array}$ \\
\hline \multicolumn{7}{|l|}{ Atopic subjects } \\
\hline \multicolumn{7}{|c|}{ Active smoking during adolescence } \\
\hline No & $13.8(71 / 515)$ & & $6.3(30 / 474)$ & & $3.4(15 / 442)$ & \\
\hline Yes & $25.8(65 / 252)$ & 1.63 (1.20 to 2.22$)$ & $18.3(42 / 229)$ & 2.07 (1.35 to 3.18$)$ & $9.7(19 / 196)$ & 2.16 (1.15 to 4.06$)$ \\
\hline \multicolumn{7}{|c|}{ Duration of active smoking (years) } \\
\hline Never & $13.8(71 / 515)$ & & $6.3(30 / 474)$ & & $3.4(15 / 442)$ & \\
\hline$\leqslant 2$ & $18.1(19 / 105)$ & 1.18 (0.74 to 1.87$)$ & $12.2(12 / 98)$ & 1.44 (0.79 to 2.64$)$ & $3.5(3 / 85)$ & $0.84(0.26$ to 2.69$)$ \\
\hline $2-4$ & $26.7(27 / 101)$ & 1.59 (1.08 to 2.34$)$ & $17.8(16 / 90)$ & 1.86 (1.07 to 3.23$)$ & $13.4(11 / 82)$ & $2.90(1.35$ to 6.21$)$ \\
\hline$>4$ & $40.5(15 / 37)$ & 2.51 (1.58 to 3.99$)$ & $35.3(12 / 34)$ & $3.87(2.16$ to 6.91$)$ & $16.7(4 / 24)$ & 3.71 (1.39 to 9.94$)$ \\
\hline \multicolumn{7}{|c|}{ Intensity of active smoking } \\
\hline Never & $13.8(71 / 515)$ & & $6.3(30 / 474)$ & & $3.4(15 / 442)$ & \\
\hline Occasionally & $14.9(7 / 47)$ & 1.01 (0.50 to 2.05 ) & $7.0(3 / 43)$ & 0.98 (0.33 to 2.89$)$ & $2.4(1 / 41)$ & 0.64 (0.09 to 4.42$)$ \\
\hline Daily $\leqslant 10$ cigs & $23.5(27 / 115)$ & 1.55 (1.04 to 2.32$)$ & $18.5(20 / 108)$ & $2.18(1.28$ to 3.71$)$ & $10.1(9 / 89)$ & $2.42(1.11$ to 5.27$)$ \\
\hline Daily $>10$ cigs & $34.8(31 / 89)$ & $2.19(1.48$ to 3.23$)$ & $24.7(19 / 77)$ & $2.63(1.54$ to 4.49$)$ & $13.8(9 / 65)$ & 3.05 (1.32 to 7.02$)$ \\
\hline \multicolumn{7}{|l|}{ Non-atopic subjects } \\
\hline \multicolumn{7}{|c|}{ Active smoking during adolescence } \\
\hline No & $5.5(45 / 825)$ & & $1.9(15 / 795)$ & & $0.8(6 / 778)$ & \\
\hline Yes & $20.8(104 / 500)$ & $3.25(2.22$ to 4.76$)$ & $9.2(40 / 436)$ & $3.92(2.01$ to 7.65$)$ & $2.3(9 / 399)$ & 2.16 (0.79 to 5.93$)$ \\
\hline \multicolumn{7}{|c|}{ Duration of active smoking (years) } \\
\hline Never & $5.5(45 / 825)$ & & $1.9(15 / 795)$ & & $0.8(6 / 778)$ & \\
\hline$\leqslant 2$ & $14.2(26 / 183)$ & 2.42 (1.48 to 3.98$)$ & $6.5(11 / 168)$ & 3.13 (1.34 to 7.33$)$ & $1.9(3 / 158)$ & $1.91(0.50$ to 7.32$)$ \\
\hline $2-4$ & $23.3(50 / 215)$ & 3.67 (2.39 to 5.63$)$ & $9.3(17 / 182)$ & 4.06 (1.90 to 8.68$)$ & $2.4(4 / 167)$ & $2.27(0.64$ to 8.06$)$ \\
\hline$>4$ & $28.4(27 / 95)$ & $4.38(2.70$ to 7.11$)$ & $15.0(12 / 80)$ & 5.98 (2.68 to 13.35 ) & $2.9(2 / 68)$ & 2.84 (0.59 to 13.58 ) \\
\hline \multicolumn{7}{|c|}{ Intensity of active smoking } \\
\hline Never & $5.5(45 / 825)$ & & $1.9(15 / 795)$ & & $0.8(6 / 778)$ & \\
\hline Occasionally & $14.6(12 / 82)$ & 2.46 (1.34 to 4.51$)$ & $6.7(5 / 75)$ & 3.11 (1.12 to 8.63$)$ & $2.9(2 / 70)$ & $2.92(0.61$ to 14.03$)$ \\
\hline Daily $\leqslant 10$ cigs & $15.8(35 / 222)$ & 2.72 (1.73 to 4.30$)$ & $5.6(11 / 198)$ & $2.68(1.14$ to 6.27$)$ & $1.6(3 / 187)$ & 1.63 (0.42 to 6.30 ) \\
\hline Daily $>10$ cigs & $28.9(56 / 194)$ & 4.41 (2.86 to 6.79$)$ & $14.8(24 / 162)$ & 6.24 (2.94 to 13.22$)$ & $2.8(4 / 141)$ & $2.42(0.70$ to 8.36$)$ \\
\hline
\end{tabular}

$\mathrm{n}$, cases; $\mathrm{N}$, total of exposed; IRR, incidence risk ratio; $\mathrm{Cl}$, confidence interval.

*Population comprises subjects without missing values for the outcome, exposure, and confounding variables.

†All models adjusted for sex, age, study centre, and duration of exposure to environmental tobacco smoke (ETS) at follow up (for further detail see Methods)

and most associations were statistically significant. The estimated IRR tended to be lower for atopic subjects. Table 4 shows the observed associations of ETS exposure with the incidence of wheeze and asthma for non-smokers. After adjustment, none of the associations reached statistical significance.

The relation between decreasing plasma $\alpha_{1}$-antitrypsin levels at baseline and the incidence of wheeze and asthma are shown in fig 2. Plasma levels of $\alpha_{1}$-antitrypsin ranged from $52.2 \mathrm{mg} / \mathrm{dl}$ to $254.0 \mathrm{mg} / \mathrm{dl}$ (median $152.0 \mathrm{mg} / \mathrm{dl}$ ). The IRR were calculated for a $25 \mathrm{mg} / \mathrm{dl}$ decrease in plasma $\alpha_{1}$ antitrypsin levels which reflects the interquartile range (IQR, the difference between the 25th and 75th percentiles) in the total study population.

In the total cohort, decreasing plasma $\alpha_{1}$-antitrypsin levels were not associated with the incidence of wheeze, wheeze without a cold, and diagnosed asthma. Smoking has been shown to be an important risk factor for respiratory disease in subjects with $\alpha_{1}$-antitrypsin deficiency. Decreasing plasma levels of $\alpha_{1}$-antitrypsin carried no statistically significant risk

Table 4 Incidence of wheeze or asthma between ages 9 and 17 in relation to exposure to environmental tobacco smoke (ETS) during adolescence for non-smokers

\begin{tabular}{|c|c|c|c|c|c|c|}
\hline & \multicolumn{2}{|l|}{ Incident wheeze } & \multicolumn{2}{|c|}{ Incident wheeze without a cold } & \multicolumn{2}{|c|}{ Incidence of diagnosed asthma } \\
\hline & $\%(\mathrm{n} / \mathrm{N})^{*}$ & $\begin{array}{l}\text { Adjusted IRR } \\
(95 \% \mathrm{Cl}) \dagger\end{array}$ & $\%(\mathbf{n} / \mathrm{N})^{*}$ & $\begin{array}{l}\text { Adjusted IRR } \\
(95 \% \mathrm{Cl}) \dagger\end{array}$ & $\%(\mathbf{n} / \mathrm{N})^{*}$ & $\begin{array}{l}\text { Adjusted IRR } \\
(95 \% \mathrm{Cl}) \dagger\end{array}$ \\
\hline \multicolumn{7}{|c|}{ ETS exposure at home at baseline $\neq$} \\
\hline No & $7.8(96 / 1234)$ & & $2.8(33 / 1171)$ & & $1.2(14 / 1136)$ & \\
\hline Yes & $9.5(57 / 597)$ & $1.22(0.87$ to 1.72$)$ & $3.9(22 / 562)$ & $1.39(0.79$ to 2.46$)$ & $2.2(12 / 534)$ & $2.00(0.84$ to 4.76$)$ \\
\hline \multicolumn{7}{|c|}{ ETS exposure at follow up } \\
\hline No & $8.0(71 / 888)$ & & $3.3(20 / 599)$ & & $1.4(12 / 841)$ & \\
\hline Yes & $8.8(84 / 952)$ & $1.04(0.74$ to 1.46$)$ ฯ & $3.7(25 / 677)$ & $1.19(0.68$ to 2.10$) \S$ & $1.7(15 / 888)$ & $1.25(0.57 \text { to } 2.73)^{\star *}$ \\
\hline \multicolumn{7}{|c|}{ Duration of ETS exposure at follow up (h/day) } \\
\hline Never & $8.0(70 / 877)$ & & $3.0(25 / 832)$ & & $1.5(12 / 809)$ & \\
\hline$\leqslant 1$ & $7.0(28 / 399)$ & $0.88(0.58$ to 1.34$)$ & $2.6(10 / 381)$ & $0.88(0.43$ to 1.82$)$ & $1.4(5 / 369)$ & 0.93 (0.33 to 2.64$)$ \\
\hline $1-5$ & $10.5(48 / 459)$ & $1.31(0.92$ to 1.86$)$ & $4.0(17 / 428)$ & 1.35 (0.74 to 2.48$)$ & $2.2(9 / 406)$ & $1.53(0.63$ to 3.70$)$ \\
\hline$>5$ & $8.1(14 / 172)$ & 1.01 (0.58 to 1.77$)$ & $3.7(6 / 164)$ & $1.24(0.52$ to 2.97$)$ & $0.6(1 / 155)$ & 0.45 (0.05 to 3.75$)$ \\
\hline
\end{tabular}

$\mathrm{n}$, cases; $\mathrm{N}$, total of exposed; IRR, incidence risk ratio; $\mathrm{Cl}$, confidence interval.

*Population comprises subjects without missing values for the outcome, exposure, and confounding variables. †All models adjusted for sex, age, and study centre (for further detail see Methods).

†Additionally adjusted for duration of ETS exposure at follow up.

Additionally adjusted for ETS exposure at home at baseline.

§Additionally adjusted for atopy.

${ }^{* *}$ Additionally adjusted for intensity of active smoking and duration of active smoking 

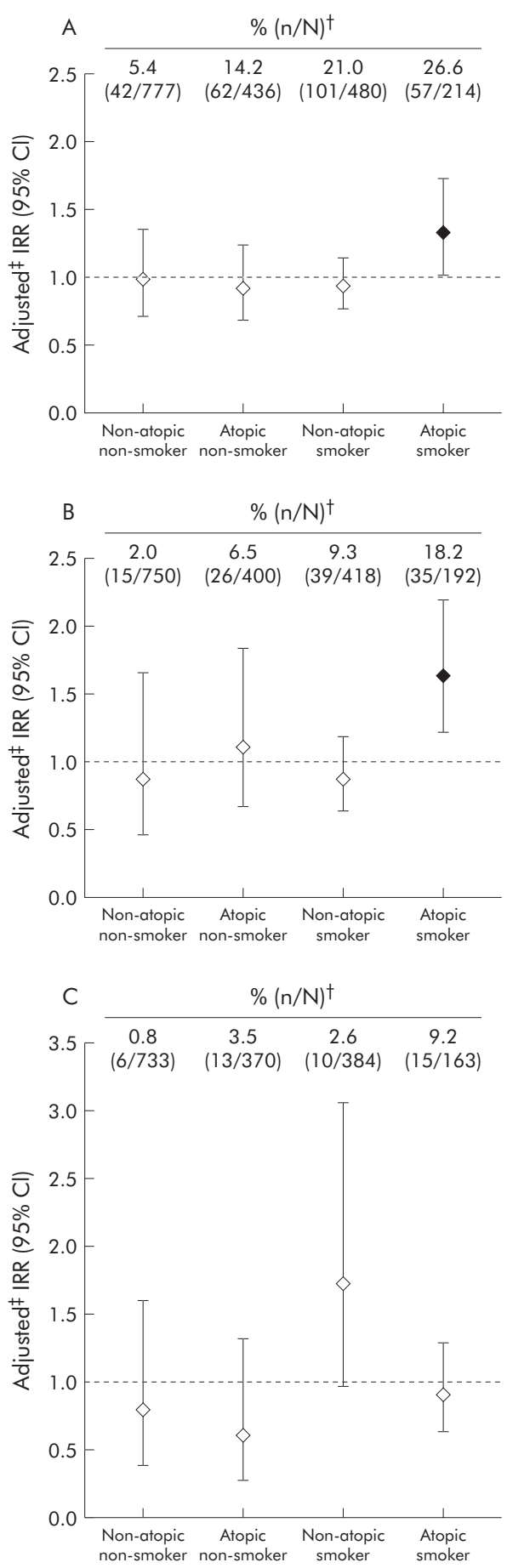

Figure 2 Incidence risk ratios (IRR) relating the incidence of (A) wheeze, (B) wheeze without a cold, and (C) diagnosed asthma between the ages of 9 and 17 years to the plasma level ${ }^{*}$ of $\alpha_{1}$-antitrypsin at baseline stratified by atopy at baseline and active smoking during adolescence. \%, incidence; $n$, cases; $N$, subjects in category; $\mathrm{Cl}$, confidence interval. *IRR refer to a $25 \mathrm{mg} / \mathrm{dl}$ decrease in plasma $\alpha_{1}$ antitrypsin levels (that is, the interquartile range in the study population). †The population comprised subjects without missing values for the outcome, exposure, and confounding variables. $\ddagger$ All models were adjusted for sex, age, and study centre (for further detail see Methods section).

for the incidence of wheeze, wheeze without a cold, and diagnosed asthma among active smokers. The same was true for non-smoking subjects exposed to ETS at follow up. An interaction between active smoking and plasma $\alpha_{1}$-antitrypsin levels, which was at least of borderline statistical significance, was observed only in relation to the incidence of diagnosed asthma $(\mathrm{p}=0.066)$.

Given the significant interaction between active smoking and atopy in relation to the incidence of wheeze, we also explored the effects of $\alpha_{1}$-antitrypsin stratified by atopy. The multiplicative interaction between plasma $\alpha_{1}$-antitrypsin levels, smoking, and atopic sensitisation had a $p$ value of 0.001 for the incidence of wheeze, $p=0.057$ for the incidence of wheeze without a cold, and $p=0.730$ for the incidence of diagnosed asthma. The estimated relative risks for wheeze and asthma with decreasing plasma $\alpha_{1}$-antitrypsin levels are therefore presented stratified for atopy and smoking status in fig 2 . There was a statistically significant association between decreasing plasma levels of $\alpha_{1}$-antitrypsin and the incidence of wheeze (1.33, 95\% CI 1.02 to 1.73$)$ and wheeze without a cold (1.64, 95\% CI 1.22 to 2.20) among atopic smokers. The incidence of diagnosed asthma was found to be related to decreasing plasma $\alpha_{1}$-antitrypsin levels in non-atopic smokers, but the statistical significance was only borderline (1.72, 95\% CI 0.96 to 3.06 ).

\section{DISCUSSION}

Our data provide strong evidence that active smoking increases the incidence of wheeze and asthma during adolescence. As expected, the increase depended on the duration and intensity of smoking. The effect of smoking was stronger in non-atopic than in atopic subjects. There was no statistically significant association between exposure to ETS and respiratory outcomes. Our findings suggest that the incidence of wheeze increases with decreasing plasma levels of $\alpha_{1}$-antitrypsin in subjects who were atopic at baseline and started active smoking during adolescence.

Participation bias is one of the most important biases in longitudinal studies. In our study 2614 participants of the baseline survey were classified as non-respondents at follow up. However, half of them had initially denied further contact and 197 could not be located for follow up (fig 1). Thus, the participation rate of those with contact agreement who could be located was $77.4 \%$, which is reasonable considering the follow up time of 7 years.

A limitation of our study, as with most epidemiological studies following childhood through to adolescence, is that information regarding the child's health in early life was reported by the parents whereas information regarding adolescence is given by the participants themselves. Subjects with a parental history of allergies were more likely to participate at follow up. However, there was no significant association between participation at follow up and parental history of asthma, which is probably more relevant as a determinant of the incidence of asthma (fig 1). Wheeze and diagnosed asthma at ages 9-11 were not associated with the uptake of smoking during adolescence (IRR 1.04 (95\% CI 0.90 to 1.20$)$ and IRR 1.08 (95\% CI 0.90 to 1.30$)$, respectively). Active smoking was assessed at follow up and, strictly speaking, it cannot be assumed that it preceded the onset of wheeze or asthma in all cases. Nevertheless, there was a clear dose-response relationship between duration or intensity of active smoking and the incidence of wheeze or asthma. We therefore believe that it is unlikely that the observed associations are due to reverse causation.

The analyses gave no evidence for differences in the observed associations between females and males and all estimates are adjusted for sex. We could not identify a significant association between exposure to ETS and the incidence of wheeze or asthma among adolescents. This is in line with some earlier publications. Nevertheless, data on this association among adolescents are still limited and the results so far are conflicting. ${ }^{11}$ 
The role of active smoking on the incidence of respiratory disease has been investigated previously. In a study in young adults (age 17-33 years) Strachan et al ${ }^{4}$ observed a positive dose-response relation of both the duration and intensity of active smoking with the incidence of asthma or wheezing illness. Larsson ${ }^{1}$ examined the incidence of asthma in subjects aged 16-19 years and Withers et al ${ }^{6}$ studied the incidence of wheeze between the ages of 7 and 15 years. Both found a positive association between active smoking and the incidence of wheeze or asthma. The effects reported by Larsson were only adjusted for sex. Withers et al did not report associations with the incidence of diagnosed asthma. Our study on almost 3000 adolescents goes beyond previous reports in that it describes the effect of active smoking on the incidence of wheeze and asthma, taking into account objective markers of atopic disease and numerous possible confounders.

The comparative epidemiology of atopic and non-atopic wheeze with regard to different patterns of risk factors has gained attention. ${ }^{24}{ }^{25}$ To contribute to this pivotal distinction, we have displayed the associations of smoking as well as plasma $\alpha_{1}$-antitrypsin levels with the incidence of wheeze and asthma stratified for atopy. The effect of active smoking on the incidence of wheeze was stronger in non-atopic subjects than in atopic subjects. This interaction between smoking and atopy has been reported previously for the association of smoking with the prevalence of wheeze, ${ }^{24}$ with bronchial responsiveness, ${ }^{26}$ and with the incidence of asthma or wheezing illness. ${ }^{4}$ The proposed explanations include selfselection of smokers or biological antagonism between atopy and smoking. In our study, non-atopic subjects took up smoking more often than atopics (IRR 1.19, 95\% CI 1.06 to 1.32). This small effect is, however, unlikely to fully explain the differences in the stratified analyses. The interaction between atopy and active smoking did not apply to the incidence of diagnosed asthma, but it has to be taken into account that the number of diagnosed asthma cases was small. The number of participants with diagnosed asthma might be underestimated owing to mild disease that had not been recognised. Furthermore, current smoking and ETS exposure at home were found to be associated with undiagnosed frequent wheezing among adolescents in the USA. ${ }^{27}$ Likewise, in Europe, underdiagnosis of asthma with its implications on treatment of the disease is still common. ${ }^{28}{ }^{29}$

We present new data on the association between plasma $\alpha_{1}$-antitrypsin levels and the incidence of wheeze and asthma stratified by atopy and active smoking. Unlike other studies we did not investigate $\alpha_{1}$-antitrypsin deficiency using genetic alterations but analysed plasma $\alpha_{1}$-antitrypsin levels independently of the genetic background and within the normal range. To provide a quantification of the observed effects, the IRR are given for a $25 \mathrm{mg} / \mathrm{dl}$ decrease in plasma $\alpha_{1}$ antitrypsin levels which reflects the interquartile range within the study population. The National Heart, Lung and Blood Institute Registry of $\alpha_{1}$-antitrypsin deficiency has used a threshold level that was set by convention to $11 \mu \mathrm{mol} / \mathrm{l}$ (approximately $60 \mathrm{mg} / \mathrm{dl}$ ) to identify subjects with $\alpha_{1}$ antitrypsin deficiency. ${ }^{30}$ In our study only one subject had a plasma $\alpha_{1}$-antitrypsin level below this threshold and more than $97 \%$ had plasma levels within the normal range of 90 $200 \mathrm{mg} / \mathrm{dl}$.

The effect of $\alpha_{1}$-antitrypsin deficiency on respiratory disease has recently been investigated, and $\alpha_{1}$-antitrypsin deficiency with its genetic alterations was subject to a review series in 2004. ${ }^{31}$ It seems that $\mathrm{Z}$ and $\mathrm{S}$ alleles, which lead to low plasma levels of $\alpha_{1}$-antitrypsin, are associated with an increased risk of developing lung and liver disease whereas null variants, with no detectable $\alpha_{1}$-antitrypsin plasma levels, may be associated with an increased risk of developing emphysema. ${ }^{32}$ However, some data from a national birth cohort study in Great Britain did show an association between $\alpha_{1}$-antitrypsin deficiency and lower respiratory tract infections in infants, but not impaired respiratory health in adults. ${ }^{33}$

In children with genetically determined $\alpha_{1}$-antitrypsin deficiency, active smoking seems to be a risk factor for lung function decline in young adults. ${ }^{15}{ }^{34}$ Cross sectional analyses of our cohort at baseline suggest that children with low levels of $\alpha_{1}$-antitrypsin $(\leqslant 116 \mathrm{mg} / \mathrm{dl})$ are at increased risk of developing pronounced decrements in pulmonary function, particularly if they are exposed to ETS. ${ }^{14}$ Further analysis showed no association between low levels of $\alpha_{1}$-antitrypsin and the prevalence of asthma, but suggested an increase in the vulnerability for lung function decrements among children with low levels of $\alpha_{1}$-antitrypsin and asthma. ${ }^{35}$ Data on the genetic background of our study population was assessed at baseline but could not be accessed for the cohort due to ethical reasons.

Since smoking has been shown to be an important risk factor for respiratory disease in subjects with $\alpha_{1}$-antitrypsin deficiency, we explored a potential interaction between plasma levels of $\alpha_{1}$-antitrypsin and smoking for the respiratory outcomes in our study population. The analyses of the incidence of diagnosed asthma but not wheeze suggested an interaction between decreasing $\alpha_{1}$-antitrypsin plasma levels and active smoking. It could be speculated that higher levels of $\alpha_{1}$-antitrypsin protect active smokers from respiratory disease by its effects against the degeneration of elastic tissue during inflammation. In our study, decreasing plasma $\alpha_{1}$-antitrypsin levels were associated with the incidence of wheeze and wheeze without a cold in atopic smokers and, although only of borderline statistical significance, with the incidence of diagnosed asthma in non-atopic smokers. We have no immediate explanation for this discrepancy between wheeze and diagnosed asthma. The relatively small number of cases of diagnosed asthma or chance may have played a part. The mechanisms by which smoking, atopy, and $\alpha_{1}$-antitrypsin may interact during chronic inflammation of the lung are not fully understood. To our knowledge, this is the first study to report a relation between relatively lower plasma $\alpha_{1}$-antitrypsin levels within the normal range, in combination with smoking and atopy, and the incidence of wheeze and asthma. If our results are confirmed, children with low plasma $\alpha_{1}$-antitrypsin levels may be a target group for smoking prevention programmes.

In conclusion, our data indicate that active smoking is an important risk factor for the incidence of wheeze and asthma during adolescence. The relative risk increases with the duration and intensity of active smoking and seems to be higher in non-atopic than in atopic subjects. Relatively lower plasma levels of $\alpha_{1}$-antitrypsin, although well above currently accepted thresholds, may increase susceptibility to respiratory disease among atopic smokers.

\section{Authors' affiliations \\ J Genuneit, G Weinmayr, P Rzehak, S K Weiland, Department of Epidemiology, University of Ulm, Germany \\ K Radon, H Dressel, D Nowak, Institute for Occupational and Environmental Medicine, Ludwig-Maximilians-University, Munich, Germany \\ D Windstetter, E von Mutius, Dr von Haunersches University Children's Hospital, Ludwig-Maximilians-University, Munich, Germany C Vogelberg, W Leupold, University Children's Hospital, Technical University, Dresden, Germany}

The study was supported by the German Ministry for Economy and Labor.

The authors declare that they have no competing or conflicting interests, and that they have no financial relationship with a commercial entity that has an interest in the subject of this manuscript. 


\section{REFERENCES}

1 Larsson L. Incidence of asthma in Swedish teenagers: relation to sex and smoking habits. Thorax 1995;50:260-4.

2 Ronmark E, Lundback B, Jonsson E, et al. Incidence of asthma in adults: report from the Obstructive Lung Disease in Northern Sweden Study. Allergy 1997;52:1071-8.

3 Dodge RR, Burrows B. The prevalence and incidence of asthma and asthmalike symptoms in a general population sample. Am Rev Respir Dis 1980;122:567-75.

4 Strachan DP, Butland BK, Anderson HR. Incidence and prognosis of asthma and wheezing illness from early childhood to age 33 in a national British cohort. BMJ 1996;312:1195-9.

5 Krzyzanowski M, Lebowitz MD. Changes in chronic respiratory symptoms in two populations of adults studied longitudinally over 13 years. Eur Respir J 1992;5:12-20.

6 Withers $\mathrm{N}$, Low L, Holgate $\mathrm{S}$, et al. The natural history of respiratory symptoms in a cohort of adolescents. Am J Respir Crit Care Med 1998;158:352-7.

7 Vesterinen E, Kaprio J, Koskenvuo M. Prospective study of asthma in relation to smoking habits among 14,729 adults. Thorax 1988;43:534-9.

8 Huovinen E, Kaprio J, Koskenvuo M. Factors associated to lifestyle and risk of adult onset asthma. Respir Med 2003;97:273-80.

9 Troisi RJ, Speizer FE, Rosner B, et al. Cigarette smoking and incidence of chronic bronchitis and asthma in women. Chest 1995; 108:1557-61.

10 Mannino DM, Homa DM, Redd SC. Involuntary smoking and asthma severity in children: data from the Third National Health and Nutrition Examination Survey. Chest 2002;122:409-15.

11 Strachan DP, Cook DG. Parental smoking and childhood asthma: longitudinal and case-control studies. Thorax 1998;53:204-12.

12 Radon K, Busching K, Heinrich J, et al. Passive smoking exposure: a risk factor for chronic bronchitis and asthma in adults? Chest 2002;122:1086-90.

13 Kabesch M, Hoefler C, Carr D, et al. Glutathione S transferase deficiency and passive smoking increase childhood asthma. Thorax 2004;59:569-73.

14 Von Ehrenstein OS, von Mutius E, Maier E, et al. Lung function of school children with low levels of alpha-1-antitrypsin and tobacco smoke exposure. Eur Respir J 2002; 19:1099-106.

15 Needham M, Stockley RA. Alpha-1-antitrypsin deficiency - 3: Clinical manifestations and natural history. Thorax 2004;59:441-5.

16 Weiland SK, Bjorksten B, Brunekreef B, et al. Phase Il of the International Study of Asthma and Allergies in Childhood (ISAAC II): rationale and methods. Eur Respir J 2004;24:406-12.

17 Weiland SK, von Mutius E, Hirsch T, et al. Prevalence of respiratory and atopic disorders among children in the East and West of Germany five years after unification. Eur Respir J 1999;14:862-70.

18 Kabesch M, Schaal W, Nicolai T, et al. Lower prevalence of asthma and atopy in Turkish children living in Germany. Eur Respir J 1999;13:577-82.
19 Burney P, Chinn S. Developing a new questionnaire for measuring the prevalence and distribution of asthma. Chest 1987;91:79-83S

20 Johansson SGO, Bieber T, Dahl R, et al. Revised nomenclature for allergy for global use: Report of the Nomenclature Review Committee of the World Allergy Organization, October 2003. J Allergy Clin Immunol 2004;113:832-6.

21 Kromeyer-Hauschild K, Wabitsch M, Kunze D, et al. Perzentile für den Bodymass-Index für das Kindes- und Jugendalter unter Heranziehung verschiedener deutscher Stichproben. Monatsschr Kinderheilkd 2001;149:807-18

22 Zou G. A modified poisson regression approach to prospective studies with binary data. Am J Epidemiol 2004; 159:702-6.

23 Greenland S. Model-based estimation of relative risks and other epidemiologic measures in studies of common outcomes and in case-control studies. Am J Epidemiol 2004;160:301-5.

24 Court CS, Cook DG, Strachan DP. Comparative epidemiology of atopic and non-atopic wheeze and diagnosed asthma in a national sample of English adults. Thorax 2002;57:951-7.

25 Kurukulaaratchy RJ, Fenn M, Matthews S, et al. Characterisation of atopic and non-atopic wheeze in 10 year old children. Thorax 2004;59:563-8.

26 Sunyer J, Anto JM, Kogevinas M, et al. Smoking and bronchial responsiveness in nonatopic and atopic young adults. Spanish Group of the European Study of Asthma. Thorax 1997;52:235-8.

27 Yeatts K, Davis KJ, Sotir M, et al. Who gets diagnosed with asthma? Frequent wheeze among adolescents with and without a diagnosis of asthma. Pediatrics 2003:111:1046-54.

28 Maziak W, von Mutius E, Beimfohr C, et al. The management of childhood asthma in the community. Eur Respir J 2002;20:1476-82.

29 Von Mutius E. A conundrum of modern times that's still unresolved. Eur Respir J 2003:22:719-20.

30 McElvaney NG, Stoller JK, Buist AS, et al. Baseline characteristics of enrollees in the National Heart, Lung and Blood Institute Registry of alpha 1-antitrypsin deficiency. Alpha-1-Antitrypsin Deficiency Registry Study Group. Chest 1997;111:394-403.

31 Stoller JK. Alpha-1-antitrypsin deficiency. Thorax 2004;59:92-3.

32 Luisetti M, Seersholm N. Alpha-1-antitrypsin deficiency - 1: Epidemiology of alpha-1-antitrypsin deficiency. Thorax 2004;59:164-9.

33 Wadsworth MEJ, Vinall LE, Jones AL, et al. Alpha-1-antitrypsin as a risk for infant and adult respiratory outcomes in a national birth cohort. Am J Respir Cell Mol Biol 2004;31:559-64.

34 Piitulainen $E$, Sveger T. Effect of environmental and clinical factors on lung function and respiratory symptoms in adolescents with alpha 1-antitrypsin deficiency. Acta Paediatr 1998;87:1120-4.

35 Von Ehrenstein OS, Maier EM, Weiland SK, et al. Alpha 1-antitrypsin and the prevalence and severity of asthma. Arch Dis Child 2004;89:230-1. 